\title{
A Qualitative Examination of Patient Experiences and Determinants of Virtual Postnatal Follow-Up Visits
}

\author{
Megan Saad \\ Queen's University \\ Sophy Chan \\ Queen's University \\ Lisa Nguyen \\ Queen's University \\ Siddhartha Srivastava \\ Queen's University \\ Ramana Appireddy ( $\square$ mrra@queensu.ca) \\ Queen's University
}

Research Article

Keywords: Telemedicine, Postpartum Period, Postnatal Care, Qualitative Research, Social Determinants of Health

Posted Date: January 25th, 2021

DOI: https://doi.org/10.21203/rs.3.rs-143006/v1

License: (1) This work is licensed under a Creative Commons Attribution 4.0 International License. Read Full License

Version of Record: A version of this preprint was published at BMC Pregnancy and Childbirth on August 7th, 2021. See the published version at https://doi.org/10.1186/s12884-021-03999-9. 


\section{Abstract}

Objective: This study aimed to understand the perceptions of new mothers using virtual care in the form of video conferencing to gain insight into the social and environmental determinants that could potentially impact compliance for post-natal follow-up visits.

Methods. Semi-structured interviews were conducted with 15 patients of Kingston Health Sciences Centre. The interviews were 20-25 minutes in length and recorded through an audio recorder. Thematic analysis was conducted in order to derive the major themes explored in this study.

Results: In general, new mothers reported high satisfaction with virtual care, emphasizing benefits related to comfort, convenience, communication, socioeconomic factors, and the ease of technology use.

Conclusions: Not only can virtual care address many of the barriers that new mothers face in accessing in-person healthcare services, but virtual care can also elucidate various social and environmental determinants responsible for facilitating access to postnatal follow-up care. Further research and clinical endeavours should focus on these various determinants (and the ways they intersect) and how they underpin patient perceptions of virtual and in-person care. Such a lens not only addresses the struggle of long-term patient compliance to maternal health care, but will additionally shed light on how to make obstetric care more equitable.

\subsection{Introduction}

A significant proportion of women experience medical complications such as hypertension and diabetes in the postpartum period 1,2 . Many of these conditions require and benefit from ongoing medical care, as long-term prognosis could lead to an elevated risk of cardiovascular disease and mortality $1,2,3$. Hypertensive disorders and gestational diabetes have been associated with a 50-300\% increase in risk for cardiovascular disease4. 5 . A multitude of factors related to pregnancy and associated medical complications can significantly affect the quality of life of new mothers6, $7,8,9$. Thus, clinical intervention in the postpartum period is significant in reducing maternal morbidity and increasing quality of life. However, the burden and demands of dealing with pregnancy and the post-partum period along with the pre-existing barriers in accessing health care (socio-demographic and geographical) can all negatively impact patient compliance in attending postnatal follow-up clinics $10 \cdot 11$. Telemedicine can serve to improve accessibility to postnatal healthcare services for this unique patient population and thus enhance patient care12.13. Virtual care allows patients to consult with their healthcare provider through digital technologies. Virtual care can be conducted through various modalities, such as email, text messaging, or audio-videoconferencing and through personal digital devices, such as a smartphone or tablet, without any additional infrastructure required14, 15, 16.

\subsubsection{Social Determinants of Health in New Mothers}

The World Health Organization defines the social determinants of health as the conditions in which people are born, grow, work, live, and age, and the wider set of forces and systems shaping the conditions of daily life17. The Social Determinants of Health (SDoH) framework posits that biological outcomes and access to health care are mediated by social inequalities 18 . In particular, gender uniquely intersects with other social and environmental determinants. As such, new mothers are often burdened by a unique set of challenges and can be disproportionately limited in their access to health care. Immigration status, language proficiency, Aboriginal status, food insecurity, poverty and rurality are known determinants that make it difficult for mothers to obtain the care they need19. However, the SDoH may uniquely impact health and healthcare access for new mothers given that considerations around accessibility may be different. Therefore, the objective of this study was to understand the experiences of new mothers using virtual visit for postnatal follow-up visits and to understand if virtual care can address challenges related to health care access.

\subsection{Methods}

Semi-structured interviews were conducted with patients being seen at the Kingston Health Sciences Centre (KHSC) for maternal postnatal follow-up virtual visits with an obstetric medicine physician. Virtual visits, via video conferencing, were supported by the Ontario Telemedicine Network (OTN)20. 31 patients who completed a virtual visit appointment between February and August 2020 were invited to participate in this study 21. A medical secretary invited all potential participants by telephone. It was decided to recruit a limited number of participants to maintain a strong level of rigor in the data collection and analysis. The purpose of using semi-structured interviews in qualitative research is to guide interviewees to speak about their lived experiences with a phenomenon openly without a pre-set answer 21 . 
The interviews were conducted over the telephone and recorded using an audio recorder and lasted 20-25 minutes. Ethics approval was obtained by the Queen's University Health Sciences Research Ethics Board.

Two study team members (S.C. and M.S.), a research associate and a medical student, conducted the telephone interviews. It was made known to the participants that the research team sought to better understand how the potential barriers of virtual care. Field notes were taken during the interviews. The interviews were transcribed verbatim by a hired transcriptionist, and the transcripts coded by S.C. and M.S. The data was coded using NVivo 12.0. Braun and Clarke's thematic analysis approach was used throughout the coding process for identifying, analyzing and reporting patterns within the data22. Consensus of the coding themes was reached through an interactive process, where S.C. and M.S. came together at every $5^{\text {th }}$ stage of the coding process to review and refine the parent and subthemes.

\subsection{Results}

Out of 31 potential participants, 15 participants were interviewed from July-August 2020. 6 patients declined to participate in the study. 9 participants signed up to participate but did not end up completing the interview following multiple attempts at follow-up. The ages of participants ranged from 22 to 41 years. All participants identified as female, and majority of participants were married, Canadian-born and of white/Caucasian ethnicity, employed, living in Kingston, ON, and had a bachelor's degree or above (Table 1). Details on travel distance, travel time, number of virtual care visits, and the medical profiles of the participants are listed in Table 2.

\subsubsection{Challenges of Being a New Mother}

Across the interviews, participants spoke broadly about their mothering experiences. Many participants spoke specifically to the challenges of being a new mother and changes they have adopted to their daily lives since having a child. Some of the changes included having to prioritize their child's needs, adopting new routines, and balancing multiple conflicting priorities. Challenges associated with these changes included scheduling difficulties for healthcare appointments or other daily activities, increased demands for planning and arranging the day, difficulty breastfeeding, time constraints associated with a busier lifestyle, and the overall burden of care on new mothers.

\subsubsection{Benefits of Virtual Care}

In describing experiences with virtual care, participants overall spoke very positively. Some of the factors that contributed to participants' positive experiences with virtual visit included those that facilitated comfort and convenience for participants, including not needing to take time off work and lose a day of income:

You didn't feel a disconnect. I was able to speak freely with [obstetrics physician] and in the comfort of my own office. I have a door, I was able to shut the door and just have the meeting during my lunch hour so it was perfect.

It's great because I don't have to worry about getting ready and making child care arrangements. I can just put my son in the chair next to me and it makes it far more accessible. Neither of us has to take time off work really.

Many participants revealed virtual care served to alleviate various difficulties associated with the domestic tasks of new mothers. These difficulties included working around the child's eating and sleeping schedule, working around the schedules of multiple children in the household, or working around the schedules of their caregivers or family members. Additional challenges included barriers associated with travel time, distance, finding parking, and cost.

It made it a lot easier 'cause it was a lot less time consuming, not having to pack up and go out. I can even do it while the baby was napping and not have to mess up their schedule, like, kids' schedules. It was a lot easier.

I found it much easier to just be able to be at home, not have to worry about getting the kids ready and long care rides or have to worry about findings someone to watch them. They were very good if I needed to take care of the baby for a second or breastfeed. There's a lot you do.

Participants also found virtual care to be relieve emotional stress related to attending the hospital.

Saving gas money, parking money, and I hate driving so it was a huge emotional stress driving to Kingston every single time. My mental health was much better for not having to go at that time. 
I think just in general making people's life better. You don't have people getting on the road on an icy day that they don't need to. I just think there's a lot of benefits to society with something like this.

Additional benefits of virtual care included fostering long-term compliance to obstetric follow-up care by facilitating emotional support and rapport with the obstetric medicine physician.

Kingston's a far drive for me so when I was near the end, especially when you're heavily pregnant, I already had that emotional support and I could trust my doctor, so just being able to do a virtual visit was huge for me. It helped my husband not have to arrange his schedule for work and it helped me still stay reassured that everything was going to be fine.

Honestly, it helped big time because I can still see [the healthcare provider] and still communicate then instead of wasting money on transportation and having to do extra time trying to get her [child] ready, getting everything done and being there on time. Where here you can just do it through the phone. If I can still be feeding her and still be doing it so it helps in the long run.

\subsubsection{Challenging Aspects of virtual visit and Virtual Care}

Few participants spoke to the negative aspects of using virtual visit. While many of the participants in this study did not experience technological difficulties, some inferred that poor internet connectivity, audio issues, and technology could serve as barrier for older patients. One participant spoke to these challenges in the context of living in a rural town:

For me it's easy to navigate. If it was my parents it would be a nightmare. They're...needs to be seen in person. It's just not gonna happen. Accessibility, we're in a rural area and we don't really even have high speed internet. We're lucky we're still not dial-up...My parents live in a place where it's hard to even get any internet. They live five minutes down the road and you have to pay for one of those special satellite things to come or get the tower in order to even get internet.

\subsection{Discussion}

The purpose of this study was to understand the experiences of new mothers using virtual care for postnatal follow-up. The data suggests that virtual visits were considered a convenient, low-barrier, and accessible modality for healthcare delivery for postnatal followup care. In the context of being a new mother, virtual visit was able to address many challenges unique to this population, such as scheduling difficulties, needing to arrange for childcare, and time constraints due to busier routines. These findings are consistent with previous literature, where patients found virtual care to be convenient, time-saving, and accessible for patients with unique physical impairments 15, 23.

\subsubsection{Virtual care as a means towards patience compliance to follow-up care}

While there have been relatively limited studies examining the use of virtual care in the form of video conferencing for maternal healthcare in the postpartum period, our results are consistent with previous literature examining patient satisfaction with virtual obstetric care in the prenatal period24. Virtual visits have been found not only be convenient, but to uphold the same level of rapport in the patient-provider encounter. In a U.S.-based cross-sectional survey examining patient's preferences for telehealth visits, almost $1 / 3^{\text {rd }}$ of participants expressed a preference for telehealth, and over $1 / 2$ of participants rated telehealth to be just as good as traditional in person care25. Likewise, our participants expressed that virtual visit was comparable or even better than in-person visit where follow-up visits do not necessitate being seen for a physical examination.

The participants in this study also expressed enthusiasm for the use of virtual visit in the follow-up care context, where the convenience of being able to see a provider at home for a simple follow-up appointment was significant in terms of comfort, convenience, and costs. This is consistent with literature examining patient experiences with telehealth for follow-up care specifically26. In other studies examining the use of telemedicine for support in early discharge from childbirth, patients also reported feeling confident with the ease of the technology and did not perceive a threat to their privacy or personal information. In a pilot project based in Sweden, patients reported feeling confident that their concerns and questions were addressed to the same degree through video conferencing and that communication with their provider was not compromised27. This may be attributed to the fact that younger mothers may already incorporate technology in their daily lives 28 . Resultantly, young mothers may more positively take up virtual care in comparison to other patient populations or age groups. 
Our participants also expressed how virtual visit was able to address barriers to accessing healthcare related to financial constraints, distance, travel time, and arranging time off work, which is consistent with previous literature examining the benefits of virtual care visits in primary care settings. These findings are also consistent with other studies exploring the use of virtual care in other patient populations $13,15,23$, 29 Overall, the perceived benefits of virtual care could provide insight into ways to increase patient compliance to post-natal follow-up care. In another study conducted by researchers at Kingston Health Sciences Centre, it was found that increasing distance from the hospital was significantly associated with poorer attendance at follow-up visits. To a less significant degree, it was also found that poorer follow up was associated with patients with a greater number of living children and women with no educational certificate, diploma, or degree10.

In our study, virtual care was found to be highly favored amongst participants living out of the city as they did not have to spend time, costs, and energy to attend to the hospital. Virtual care was also found to be useful for women with multiple children in our study as they were not required to make extra childcare arrangements, find caretakers, and spend associated costs. This was particularly relevant throughout the ongoing COVID-19 pandemic, as patients were not permitted to bring other children to the visits in order to prevent unwanted exposure. Several other participants recalled that they had forgotten to attend their appointments. However, all felt inclined to use virtual visits once they were reminded to do so through phone call by the clinic secretary due to its perceived ease of use. Other participants alluded that virtual care would not interrupt their source of income as they were able to conduct the virtual session otherwise.

\subsubsection{Virtual care and the Social Determinants of Health}

Virtual care appears to be an important modality for increasing compliance to post-natal follow-up care. This is likely due to the fact that virtual care addresses the various social and environmental factors that intersect to impact health care access. Income, geography, and educational background are commonly understood as some of the most significant social determinants of health 18,30 , 31. Compounded by domestic tasks and expectations, women may feel overwhelmed, overburdened, or disinclined to attend postnatal follow-up clinics32. Since virtual care can be conducted at a place comfortable for the patient and at their own schedule, it may become easier for women to attend to attend regular follow-up visits for maternal health monitoring. As a result, virtual care should be positioned not only as a tool to facilitate compliance in follow-up, but as a tool to evaluate the various social and environmental determinants that may encourage or deter patients from attending follow-up clinics.

Our study did allude to one major limitation of virtual visit, in that the internet connection can vary considerably between patients and pose a potential barrier for conducting virtual care appointments33. This limitation can be exacerbated by various socioeconomic factors such as rurality or financial constraints. Patients who are unable to afford a high-speed internet connection or those who live in rural areas with poor connectivity may find themselves limited in their ability to access virtual care appointments 23 . This finding is consistent with previous literature indicating that virtual modalities for healthcare delivery in primary care can be limited when it comes to connection issues $34,35,36,37,38$.

\subsubsection{Limitations of the study}

This study was limited by the relative homogeneity of the sample. As many of the participants were white/Caucasian, married, Canadianborn, middle-class, well educated women, the perceived positive and negative aspects of virtual visit could be different if a more heterogenous sample was interviewed. For example, as Canada is an immigrant-dense country, language barriers, especially if virtual visit is not offered in multiple languages, could potentially be a limiting factor. Overall, however, participants were highly satisfied with the virtual visit platform for postnatal follow-up appointment visits and the comfort and convenience it provides to participants are relevant across patient demographics. The research team also acknowledges that the sample size for this study is relatively small. This could be attributed to a large number of patients who had declined to participate as well as the research team's decision to take an ethnographic approach to the data in order to draw out rich details from the participants.

\subsubsection{Future Directions}

While this study showed that new mothers found virtual visit to be a suitable modality of healthcare delivery for postnatal follow-visits, our interviews alluded to a variety of challenges that new mothers experience that may differentially impact their ability to seek care. Therefore, future studies should investigate barriers to accessing in-person healthcare services for new mothers in order to better understand the unique determinants and barriers of this patient population. Intersectionality theory would serve well to illuminate the 
connections between social determinants and barriers to virtual care. Furthermore, virtual care has the potential to significantly shift the landscape of healthcare delivery in the COVID era, and further research should specifically examine patient experiences of virtual visit in relation to the ongoing pandemic.

\subsection{Conclusion}

Qualitative interviews with new mothers who have used virtual care in the form of virtual visit for postnatal follow-up appointment visits revealed high satisfaction with virtual care, emphasizing benefits in terms of comfort, convenience, communication, socioeconomic factors, and the ease of technology use. In the follow-up care context, our findings suggest that virtual care increases accessibility and ease of follow-up care for patients with unique barriers to accessing healthcare services. Such a lens not only addresses the struggle of long-term patient compliance to maternal health care, but will also shed light on how to make obstetric care more equitable. Future directions should seek to examine the barriers to accessing in-person healthcare services unique to new mothers and examining the applicability of virtual visit for this patient population in the context of the ongoing COVID-19 pandemic.

\section{Declarations}

\section{Ethics approval and consent to participate}

All procedures in this study were conducted in accordance with the Queen's University Health Sciences Review Ethics Board (\# 6026701). Verbal informed consent was obtained from the patient(s) for their anonymized information to be published in this article. All methods were carried out in accordance with relevant guidelines and regulations.

\section{Consent for publication}

Verbal consent was obtained from all participants. While the authors of this study understand that the Journal has a firm stance on attaining written consent, we would like to ask the Editors to make an exception for our study. This study was conducted while provincial and institutional lockdowns at the Kingston General Hospital were in place due to COVID-19. At that time, it was discouraged to meet with persons outside the immediate family circle for non-essential activities. Further, many ambulatory clinics at the Kingston General Hospital were reduced or even cancelled in light of COVID-19. Given also that many of our participants lived rurally, these reasons made it extremely difficult for our research team to attain written consent as patients and researchers were both expected to stay at home. While written consent through email is a possible alternative, the Queen's University Health Sciences Research Ethics board also pressed our research team to seek verbal consent primarily as it could potentially place undue burden for patients to have to read and return signature forms over email. We have email records of these requests if the editors would like a copy. For these reasons, our research team decided to attain verbal consent from the participants. Thus, we ask the Editorial Board for consideration over why the research team decided to obtain verbal consent instead.

\section{Availability of data and materials}

As per the conditions with the Queen's University's Health Sciences Research Ethics Board, only the study team and the hired transcriber have access to the research data.

\section{Competing interests}

RA reports research grants from CIHR, PSI Foundation, Ontario, Canada Health Infoway, Department of Medicine, Queen's University, Southeastern Ontario Academic Medical Organization, Kingston General Hospital Research Institute.

\section{Funding}

The author(s) disclosed receipt of the following financial support for the research, authorship, and/or publication of this article. This work was supported by the PSI Foundation under Grant \#19-31.

\section{Authors' contributions}

M.S. and S.C were involved in recruitment, data collection, data analysis, and the writing of the manuscripts. R.A. was responsible for the conception of the study. L.N. and S.S were involved with recruitment and conceptualizing the recruitment strategy. All authors reviewed all iterations of the manuscript. 
The study team would like to acknowledge and thank all the participants for sharing their stories for this study.

\section{Author details:}

School of Medicine, Queen's University, Kingston, Ontario, Canada

Megan Saad

Department of Medicine, Queen's University, Kingston, Ontario, Canada,

Sophy Chan', Lisa Nguyen, Siddhartha Srivastava, Ramana Appireddy

\section{References}

1. Katsi V, Skalis G, Vamvakou G, et al. Postpartum hypertension. Curr Hypertens Rep. 2020;22:58. Available at https://www.ncbi.nlm.nih.gov/pubmed/32761267.

2. Ma RCW, Schmidt MI, Tam WH, et al. Clinical management of pregnancy in the obese mother: Before conception, during pregnancy, and post partum. Lancet Diabetes Endocrinol. 2016;4:1037-49. Available at https://www.ncbi.nlm.nih.gov/pubmed/27743977.

3. ACOG. Committe opinionoptimizing postpartum care. The Americal College of Obstretrics and Gynecologists; 2018 May 2018.

4. Fraser A, Nelson SM, Macdonald-Wallis C, et al. Associations of pregnancy complications with calculated cardiovascular disease risk and cardiovascular risk factors in middle age: The avon longitudinal study of parents and children. Circulation (New York, NY). 2012;125:1367-80.

5. Cusimano MC, Pudwell J, Roddy M, et al. The maternal health clinic: An initiative for cardiovascular risk identification in women with pregnancy-related complications. American journal of obstetrics and gynecology. 2014;210:438.e1-.e9.

6. Rezaei N, Tavalaee Z, Sayehmiri K, et al. The relationship between quality of life and methods of delivery: A systematic review and meta-analysis. Electron Physician. 2018;10:6596-607. Available at https://www.ncbi.nlm.nih.gov/pubmed/29881521.

7. Martinez-Galiano JM, Hernandez-Martinez A, Rodriguez-Almagro J, et al. Women's quality of life at 6 weeks postpartum: Influence of the discomfort present in the puerperium. Int J Environ Res Public Health. 2019;16. Available at https://www.ncbi.nlm.nih.gov/pubmed/30658406.

8. Kohler S, Sidney Annerstedt K, Diwan V, et al. Postpartum quality of life in indian women after vaginal birth and cesarean section: A pilot study using the eq-5d-5I descriptive system. BMC Pregnancy Childbirth. 2018;18:427. Available at https://www.ncbi.nlm.nih.gov/pubmed/30373545.

9. Bai G, Korfage IJ, Mautner E, et al. Determinants of maternal health-related quality of life after childbirth: The generation $r$ study. Int $J$ Environ Res Public Health. 2019;16. Available at https://www.ncbi.nlm.nih.gov/pubmed/31487782.

10. Nowik CMMDMPA, Pudwell JMPH, Smith GNMDPF. Evaluating the postpartum maternal health clinic: How patient characteristics predict follow-up. Journal of Obstetrics and Gynaecology Canada (JOGC). 2016;38:930-5.

11. Kornelsen J. Rural women's experiences of maternity care, implications for policy and practice. 2005.

12. Call VR, Erickson LD, Dailey NK, et al. Attitudes toward telemedicine in urban, rural, and highly rural communities. Telemed J E Health. 2015;21:644-51. Available at https://www.ncbi.nlm.nih.gov/pubmed/25839334.

13. Hollander JE, Carr BG. Virtually perfect? Telemedicine for covid-19. The New England journal of medicine. 2020;382:1679-81.

14. Lougheed T. Time to embrace the promise of virtual health care. Canadian Medical Association Journal. 2019;191:E320-E1.

15. Appireddy R, Khan S, Leaver C, et al. Home virtual visits for outpatient follow-up stroke care: Cross-sectional study. Journal of medical Internet research. 2019;21:e13734.

16. Association CM, editor Virtual care in canada: Discussion paper. CMA Health Summit [Internet]; 2019.

17. CSDH. Final report of the commission on social determinants of health. Geneva: World Health Organization; 2008.

18. Bambra C, Gibson M, Sowden A, et al. Tackling the wider social determinants of health and health inequalities: Evidence from systematic reviews. Journal of epidemiology and community health (1979). 2010;64:284 - 91.

19. Wilson-Mitchell K, Rummens J. Perinatal outcomes of uninsured immigrant, refugee and migrant mothers and newborns living in toronto, canada. International journal of environmental research and public health. 2013;10:2198-213.

20. OTN. Virtual care organizations | ontario health teams - otn.Ca: Ontario Telemedicine Network, Ontario Health; 2020 [cited 2020 May 2]. Available at https://www-origin.otn.ca/providers/ohts/.

Page $7 / 13$ 
21. Kvale S, Brinkmann S. Interviews: Learning the craft of qualitative research interviewing. Thousand Oaks, CA: SAGE; 2008.

22. Smith JA. Qualitative psychology: A practical guide to research methods. 2003.

23. Chan S, O'Riordan A, Appireddy R. Exploring the determinants and experiences of senior stroke patients with virtual care. Canadian Journal of Neurological Sciences. 2020:1-23.

24. Pflugeisen BM, Mou J. Patient satisfaction with virtual obstetric care. Matern Child Health J. 2017;21:1544-51. Available at https://www.ncbi.nlm.nih.gov/pubmed/28176034.

25. Polinski JM, Barker T, Gagliano N, et al. Patients' satisfaction with and preference for telehealth visits. Journal of general internal medicine: JGIM. 2015;31:269-75.

26. Donelan K BE, Sossong S, Michael C, Estrada JJ, Cohen AB, Wozniak J, Schwamm LH. Patient and clinician experiences with telehealth for patient follow-up care. Am J Manag Care. 2019;25:40-4.

27. Lindberg I, Christensson K, Öhrling K. Parents' experiences of using videoconferencing as a support in early discharge after childbirth. Midwifery. 2009;25:357-65.

28. Corey S, Meghan G. Generation z: A century in the making: Taylor and Francis; 2018.

29. Dewar S, Lee PG, Suh TT, et al. Uptake of virtual visits in a geriatric primary care clinic during the covid-19 pandemic. Journal of the American Geriatrics Society (JAGS). 2020;68:1392-4.

30. Bates LM, Hankivsky O, Springer KW. Gender and health inequities: A comment on the final report of the who commission on the social determinants of health. Social Science \& Medicine. 2009;69:1002-4.

31. Jackson SF, Birn A, Fawcett SB, et al. Synergy for health equity: Integrating health promotion and social determinants of health approaches in and beyond the americas. Rev Panam Salud Publica. 2013;34:473-80.

32. Spitzer DL. Engendering health disparities. Canadian Journal of Public Health / Revue Canadienne de Sante'e Publique. 2005;96:s96s. Available at http://www.jstor.org/stable/41994461.

33. Crawford A, Serhal E. Digital health equity and covid-19: The innovation curve cannot reinforce the social gradient of health. J Med Internet Res. 2020;22:e19361. Available at https://www.ncbi.nlm.nih.gov/pubmed/32452816.

34. Powell RE, Henstenburg JM, Cooper G, et al. Patient perceptions of telehealth primary care video visits. Ann Fam Med. 2017;15:2259. Available at https://www.ncbi.nlm.nih.gov/pubmed/28483887.

35. Kruse CS, Karem P, Shifflett K, et al. Evaluating barriers to adopting telemedicine worldwide: A systematic review. Journal of Telemedicine and Telecare. 2016;24:4-12.

36. Mehta SJ. Telemedicine's potential ethical pitfalls. The Virtual mentor. 2014;16:1014-7.

37. West DM, Miller EA. The digital divide in public e-health: Barriers to accessibility and privacy in state health department websites. Journal of Health Care for the Poor and Underserved. 2006;17:652-67.

38. Vogel L. Canada has long way to go on virtual care. CMAJ: Canadian Medical Association journal = journal de l'Association medicale canadienne. 2020;192:E227-E8.

\section{Tables}

Table 1: Sociodemographic data of all participants $(n=15)$ 


\begin{tabular}{|c|c|}
\hline Variable & Number (\%) \\
\hline \multicolumn{2}{|l|}{ Age categories } \\
\hline $20-24$ & $1(7 \%)$ \\
\hline $25-29$ & $2(13 \%)$ \\
\hline $30-34$ & $6(40 \%)$ \\
\hline $35-39$ & $4(27 \%)$ \\
\hline $40-44$ & $2(13 \%)$ \\
\hline Gender (females). & $15(100 \%)$ \\
\hline \multicolumn{2}{|l|}{ Ethnicity. } \\
\hline White/Caucasian & $8(53 \%)$ \\
\hline South Asian & $1(7 \%)$ \\
\hline African & $1(7 \%)$ \\
\hline Portuguese & $1(7 \%)$ \\
\hline Arab & $1(7 \%)$ \\
\hline Unknown & $3(20 \%)$ \\
\hline \multicolumn{2}{|l|}{ Employment } \\
\hline Healthcare Sector & $6(40 \%)$ \\
\hline Education Sector & $2(13 \%)$ \\
\hline Administration & $2(13 \%)$ \\
\hline Creative Professional & $1(7 \%)$ \\
\hline Student & $1(7 \%)$ \\
\hline Unemployed & $1(7 \%)$ \\
\hline Unknown & $2(13 \%)$ \\
\hline \multicolumn{2}{|l|}{ Education } \\
\hline High School & $1(7 \%)$ \\
\hline College Diploma & $2(13 \%)$ \\
\hline Bachelor's Degree & $6(40 \%)$ \\
\hline Master's Degree & $2(13 \%)$ \\
\hline $\mathrm{PhD}$ & $1(7 \%)$ \\
\hline Unknown & $3(20 \%)$ \\
\hline \multicolumn{2}{|l|}{ Place of Residence } \\
\hline Urban (in Kingston, ON) & $5(33 \%)$ \\
\hline Urban (Outside Kingston, ON) & $4(27 \%)$ \\
\hline Rural (Outside Kingston, ON) & $6(40 \%)$ \\
\hline \multicolumn{2}{|l|}{ Household Income } \\
\hline$\$ 0$ to $\$ 30,000$ & $3(20 \%)$ \\
\hline$\$ 30,000$ to $\$ 59,999$ & $2(13 \%)$ \\
\hline$\$ 60,000$ to $\$ 89,999$ & $3(20 \%)$ \\
\hline
\end{tabular}

Page 9/13 


\begin{tabular}{|ll|}
\hline$\$ 90,000$ to $\$ 119,999$ & $3(20 \%)$ \\
\hline$\$ 120,000$ to $\$ 149,999$ & $0(0 \%)$ \\
\hline Unknown & $1(7 \%)$ \\
\hline Immigrant Status & $3(20 \%)$ \\
\hline Canadian-Born & \\
\hline Non-Canadian Born & $9(60 \%)$ \\
\hline Unknown & $3(20 \%)$ \\
\hline Marital Status & $3(20 \%)$ \\
\hline Married & $13(87 \%)$ \\
\hline Unmarried (in a relationship) & $1(7 \%)$ \\
\hline Unmarried (single) & $1(7 \%)$ \\
\hline
\end{tabular}

Table 2: Travel time, number of virtual visits, and medical profiles of participants 


\begin{tabular}{|c|c|c|c|c|c|c|c|}
\hline Patient & Age & $\begin{array}{l}\text { Two-way } \\
\text { travel } \\
\text { Distance } \\
(\mathrm{km})\end{array}$ & $\begin{array}{l}\text { Two-way } \\
\text { travel time } \\
\text { (min) }\end{array}$ & $\begin{array}{l}\text { Number of } \\
\text { virtual visits }\end{array}$ & $\begin{array}{l}\text { Gravida- } \\
\text { para/TPAL } \\
\text { status }\end{array}$ & Pregnancy status & Medical conditions \\
\hline $\begin{array}{l}\text { Patient } \\
1\end{array}$ & 36 & 160 & 132 & 1 & G4T1A2L1 & Postpartum & $\begin{array}{l}\text { Pregnancy related } \\
\text { pulmonary embolism }\end{array}$ \\
\hline $\begin{array}{l}\text { Patient } \\
2\end{array}$ & 35 & 44.8 & 50 & 3 & G2T2 & Postpartum & Hypertension \\
\hline $\begin{array}{l}\text { Patient } \\
3\end{array}$ & 34 & 1180 & 762 & 1 & $\mathrm{G} 2 \mathrm{P} 1 \mathrm{~A} 1$ & Postpartum & Gestational hypertension \\
\hline $\begin{array}{l}\text { Patient } \\
4\end{array}$ & 34 & 36.2 & 48 & 1 & G2 P2 & Postpartum & $\begin{array}{l}\text { Hypertension; gestational } \\
\text { diabetes; mental health } \\
\text { disorder; }\end{array}$ \\
\hline $\begin{array}{l}\text { Patient } \\
5\end{array}$ & 34 & 7.4 & 14 & 3 & G1 P1 & Postpartum & $\begin{array}{l}\text { Preeclampsia; } \\
\text { hypertension; iron } \\
\text { deficiency anemia }\end{array}$ \\
\hline $\begin{array}{l}\text { Patient } \\
6\end{array}$ & 34 & 145.4 & 810 & 2 & $\begin{array}{l}\text { G2P3 (G1 was } \\
\text { twins) }\end{array}$ & Postpartum & $\begin{array}{l}\text { Postpartum hypertension; } \\
\text { tachycardia; preeclampsia; }\end{array}$ \\
\hline $\begin{array}{l}\text { Patient } \\
7\end{array}$ & 32 & 6.6 & 12 & 2 & G3P2A1 & Postpartum & $\begin{array}{l}\text { Chronic hypertension; } \\
\text { Bell's palsy; proteinuria; }\end{array}$ \\
\hline $\begin{array}{l}\text { Patient } \\
8\end{array}$ & 31 & 6 & 10 & 1 & $\mathrm{G} 2 \mathrm{P} 2$ & Postpartum & $\begin{array}{l}\text { Hypertension, celiac } \\
\text { disease, thyroid nodularity; } \\
\text { thrombocytopenia; }\end{array}$ \\
\hline $\begin{array}{l}\text { Patient } \\
9\end{array}$ & 28 & 55 & 64 & 3 & G1P0 & Antepartum & $\begin{array}{l}\text { Lymphadenopathy and } \\
\text { splenomegaly NDY, } \\
\text { chronic headache, } \\
\text { borderline high blood } \\
\text { pressure, overweight, } \\
\text { Herpes Zoster (early } \\
\text { pregnancy), endometriosis }\end{array}$ \\
\hline $\begin{array}{l}\text { Patient } \\
10\end{array}$ & 28 & 160.2 & 108 & 1 & $\mathrm{G} 2 \mathrm{P} 2$ & Postpartum & $\begin{array}{l}\text { Pulmonary embolism, } \\
\text { postpartum anemia } \\
\text { secondary to postpartum } \\
\text { hemorrhage; irritable } \\
\text { bowel syndrome, PTSD; }\end{array}$ \\
\hline $\begin{array}{l}\text { Patient } \\
11\end{array}$ & 22 & 56 & 64 & 1 & G1P1 & Postpartum & $\begin{array}{l}\text { Episodic hypotension; } \\
\text { arrhythmia }\end{array}$ \\
\hline $\begin{array}{l}\text { Patient } \\
12\end{array}$ & 41 & 30.6 & 44 & 2 & G2T0A1L0 & Antepartum & $\begin{array}{l}\text { Pre-existing/chronic } \\
\text { hypertension; iron } \\
\text { deficiency anemia; }\end{array}$ \\
\hline $\begin{array}{l}\text { Patient } \\
13\end{array}$ & 37 & 19.2 & 30 & 1 & G2T1P1A0L1 & Postpartum & $\begin{array}{l}\text { Allergic rhinitis, asthma, } \\
\text { acid reflux }\end{array}$ \\
\hline $\begin{array}{l}\text { Patient } \\
14\end{array}$ & 40 & 6.4 & 16 & 4 & G4P2A2 & Postpartum & $\begin{array}{l}\text { Type } 1 \text { diabetes; } \\
\text { postpartum hypertension }\end{array}$ \\
\hline Patient 15 & 36 & 168 & 130 & 1 & G4T1A2L1 & Postpartum & $\begin{array}{l}\text { Pulmonary } \\
\text { embolism }\end{array}$ \\
\hline
\end{tabular}

\section{Figures}




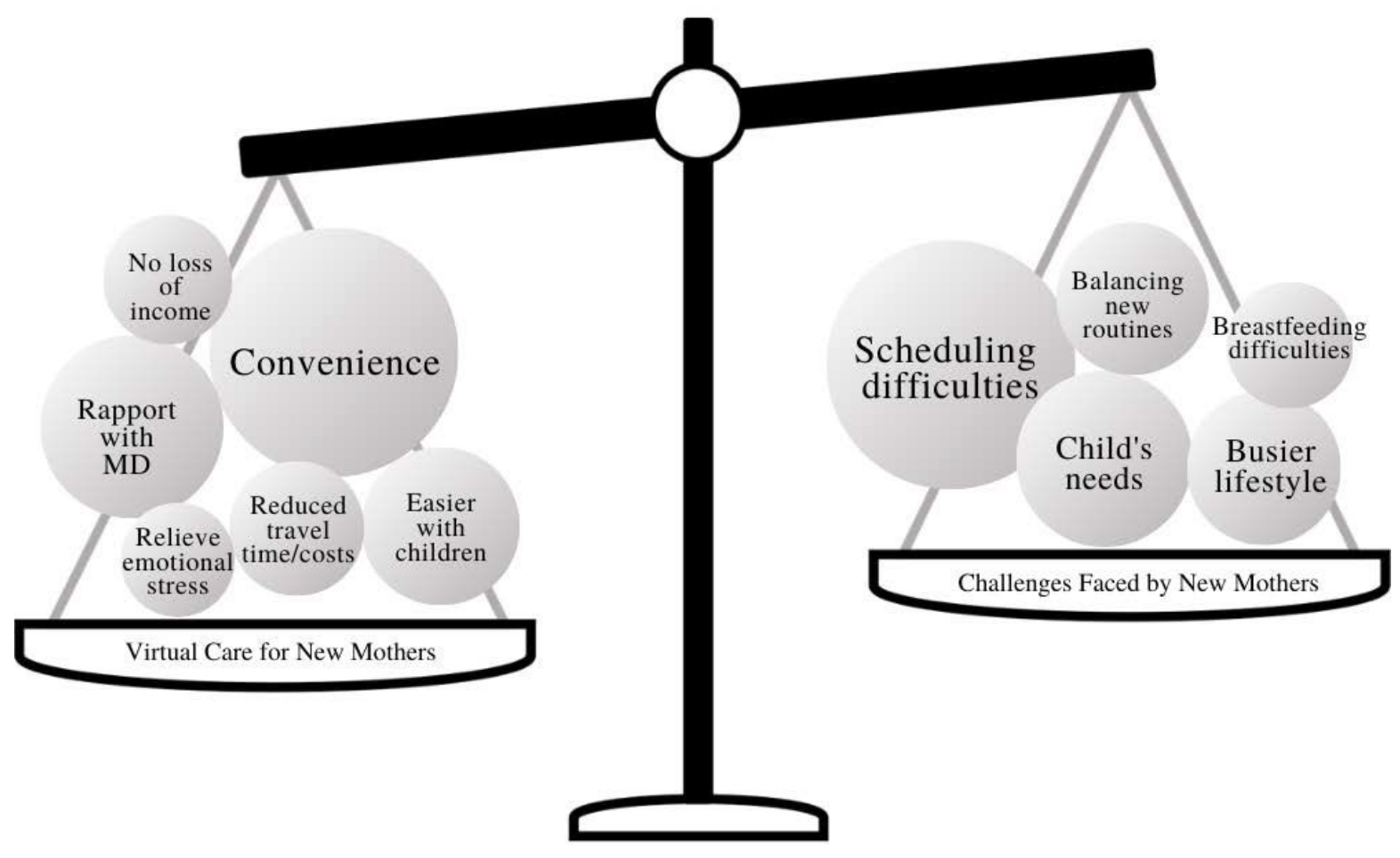

Figure 1

Two broad umbrella themes that emerged through second stage coding 


$$
\begin{aligned}
& \text { Closeness with health care provider } \\
& \text { Transportation costs } \\
& \text { Take time off work } \\
& \text { Residents \& Inconsistency of care } \\
& \text { Breastfeeding discourses } \\
& \text { COVID \& Lifestyle Changes Beneficial for COVID } \\
& \text { Child's schedule }{ }^{\text {Reduce costs }} \\
& \text { COVID as a restriction No need for childcare } \\
& \text { COVID as a restriction Quicker } \\
& \text { Similar to in-person visit } \\
& \text { Physical examination missing } \\
& \text { Convenient No support available } \\
& \text { Comfort of own hame hamily as support } \\
& \text { childcare arrangements }
\end{aligned}
$$

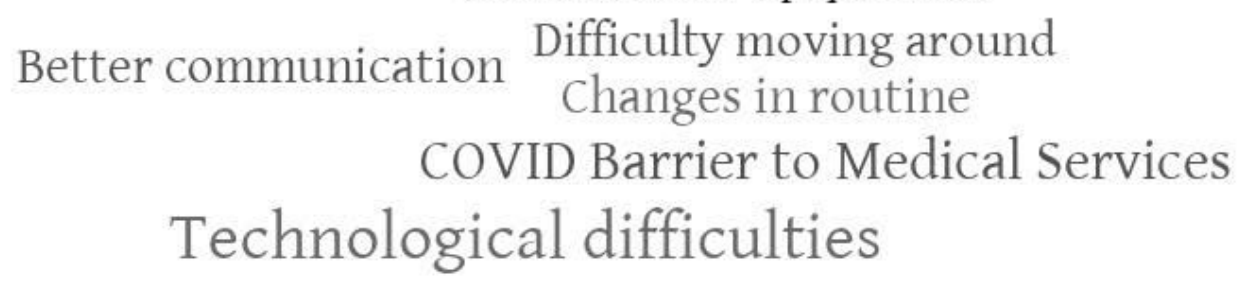

Health issues

No need to travel

Figure 2

Word map of the 30 most frequently occurring themes in the study. The presented themes in this word map were referenced at least 2 times.

\section{Supplementary Files}

This is a list of supplementary files associated with this preprint. Click to download.

- InterviewGuide.docx 